\title{
Detectability of Target Lesion During CT-Guided Tumor Ablations: Impact on Ablation Outcome
}

\section{Nachweisbarkeit der Zielläsion bei CT-gesteuerten Tumorablationen: Auswirkungen auf das Ablationsergebnis}

Authors

Emona Barzakova ${ }^{1}$, Niveditha Senthilvel ${ }^{1}$, Philipp Bruners ${ }^{1}$, Sebastian Keil' ${ }^{1}$, Georg Lurje ${ }^{2}$, Markus Zimmermann', Christiane K Kuhl' ${ }^{1}$, Peter Isfort ${ }^{1}$

Affiliations

1 Department of Diagnostic and Interventional Radiology, University Hospital RWTH Aachen, Germany

2 Department of Surgery and Transplantation, University Hospital RWTH Aachen, Germany

Key words

microwave ablation, radiofrequency (RF) ablation,

liver metastases, image guidance

received 18.04.2021

accepted 07.10.2021

published online 18.11.2021

Bibliography

Fortschr Röntgenstr 2022; 194: 515-520

DOI 10.1055/a-1669-9342

ISSN 1438-9029

(C) 2021. Thieme. All rights reserved.

Georg Thieme Verlag KG, Rüdigerstraße 14,

70469 Stuttgart, Germany

Correspondence

Emona Barzakova

Department of Diagnostic and Interventional Radiology,

University Hospital RWTH Aachen, Pauwelsstreet 30,

52074 Aachen, Germany

Tel.: +49/2 41/8037390

ebarzakova@ukaachen.de

\section{ABSTRACT}

Purpose Small hepatic malignancies scheduled for CT-guided percutaneous ablation may have been identified in the hepatobiliary phase of liver MRI or in a specific phase of multi-phase CT but may be occult on unenhanced $\mathrm{CT}$ used to guide the ablation. We investigated whether the detectability of the target lesion would impact the efficacy of CT-guided hepatic tumor ablations.

Materials and Methods We included 69 patients with 99 malignant liver lesions (25 primary, 44 metastases) who underwent IRE $(n=35)$, RFA $(n=41)$, or MWA $(n=23)$ between $01 / 2015$ and $06 / 2018$. All procedures were performed under CT guidance. Lesions not detectable on CT (NDL) were targeted through identification of anatomical landmarks on preinterventional contrast-enhanced CT or MRI. Rates of incomplete ablation, size of ablation zone, local tumor recurrence, intrahepatic progression-free survival (ihPFS), and adverse event rates were compared for detectable lesions (DL) vs. NDL.

Results 40 lesions were NDL, and 59 lesions were DL on unenhanced CT. The mean follow-up was 16.2 months (14.8 for DL and 18.2 for NDL). The mean diameter of NDL and DL was similar (12.9 mm vs. $14.9 \mathrm{~mm}$ ). The mean ablation zone size was similar ( $37.1 \mathrm{~mm}$ vs. $38.8 \mathrm{~mm}$ ). Incomplete ablation did not differ between NDL vs. DL (5.0\% [2/40; $0.6-16.9 \%]$ vs. $3.4 \%$ [2/59; 0.4-11.7\%]), nor did local tumor recurrence (15.4\% [6/39; $5.7 \%-30.5 \%$ vs. $16.9 \%$ [10/59; 8.4-29.0\%]), or median ihPFS (15.5 months vs. 14.3 months). Conclusion Target lesion detectability on interventional CT does not have a significant impact on outcome after percutaneous liver ablation when anatomical landmarks are used to guide needle placement.

Key Points:

- Liver tumors can be successfully ablated even if they are not detectable on the navigational CT scan.

- Anatomical landmarks should be used and compared to preinterventional imaging.

\section{Citation Format}

- Barzakova E, Senthilvel N, Bruners P et al. Detectability of Target Lesion During CT-Guided Tumor Ablations: Impact on Ablation Outcome . Fortschr Röntgenstr 2022; 194: 515520

\section{ZUSAMMENFASSUNG}

Ziel Intrahepatische maligne Läsionen, geplant für CT-gesteuerte perkutane Ablation, können MR-tomographisch oder CT-graphisch in einer bestimmten Kontrastmittelphase abgrenzbar sein, jedoch okkult in der nativen CT-Untersuchung, genutzt zur Planung der Ablation. Ziel dieser Studie ist zu untersuchen, ob die Abgrenzbarkeit der Zielläsion in der Planungsuntersuchung einen Einfluss auf das kurz- und mittelfristige Ablationsergebnis hat.

Material und Methoden Es wurden 69 Patienten mit insgesamt 99 malignen Leberläsionen (25 Primärtumoren, $44 \mathrm{Me}-$ tastasen) eingeschlossen, die zwischen 01/2015 und 06/2018 
irreversibler Elektroporation ( $\mathrm{n}=35$ ), Radiofrequenzablation $(n=41)$ oder Mikrowellenablation $(n=23)$ unterzogen wurden. Alle Verfahren wurden unter CT-Führung durchgeführt. Läsionen, die in der Planungs-CT nicht nachweisbar waren (NDL), wurden durch die Korrelation zu anatomischen Landmarken in der kontrastverstärkten CT oder MRT-Voruntersuchung lokalisiert. Es wurden die Raten unvollständiger Ablation, lokalen Tumorrezidivs, die Größe der Ablationszone, das intrahepatische progressfreie Überleben (ihPFS) und die Komplikationsraten für nachweisbare Läsionen (DL) gegenüber NDL verglichen.

Ergebnisse 40 Läsionen waren NDL, 59 Läsionen waren DL auf die native Planungs-CT. Die mittlere Beobachtungsdauer war 16,2 Monate (14,8 für DL und 18,2 für NDL). Die mittleren Durchmesser von NDL und DL waren ähnlich $(12,9 \mathrm{~mm}$ vs. $14,9 \mathrm{~mm})$. Die mittleren Ablationszonengrößen waren ähnlich $(37,1 \mathrm{~mm}$ vs. $38,8 \mathrm{~mm})$. Es zeigten sich keine wesent- lichen Unterschiede zwischen NDL und DL bezüglich der Häufigkeit unvollständiger Ablationen (5,0\% [2/40; 0,6\%-16,9\%] gegenüber $3,4 \%[2 / 59 ; 0,4 \%-11,7])$, des Auftretens eines lokalen Tumorrezidivs (15,4\% [6/39; 5,7\%-30,5\%] gegenüber $16,9 \%[10 / 59 ; 8,4 \%-29,0])$ oder des medianen ihPFS (15,5 Monate gegenüber 14,3 Monate).

Schlussfolgerung Die Nachweisbarkeit der Zielläsion in dem periinterventionellen Planungs-CT hat keinen signifikanten Einfluss auf das Ergebnis nach perkutanen Leberablationen, wenn anatomische Landmarken zur Nadelplatzierung genutzt werden.

\section{Kernaussagen:}

- Lebertumoren können erfolgreich abladiert werden, auch wenn sie in dem nativen Planungs-CT nicht nachweisbar sind.

- Anatomische Landmarken sollten verwendet und mit der präinterventionellen Bildgebung verglichen werden.

\section{Introduction}

Percutaneous ablation, e.g., microwave (MWA), radiofrequency ablation (RFA), or irreversible electroporation (IRE), is a wellestablished option for the treatment of selected hepatic tumors [1-6]. Successful ablation needs to cover the whole lesion including a sufficient safety margin of at least $5-10 \mathrm{~mm}$ beyond the tumor margin [7-9], while critical anatomic structures need to be spared. High-quality imaging is an important prerequisite to determine the ablation method of choice [10]. However, some tumors might be challenging to treat because they are associated with transient enhancement on multiphase $\mathrm{CT}$, or are only visible on MRI, or even only on specific MRI sequences such as diffusionweighted imaging, or hepatobiliary-phase imaging after liverspecific contrast.

On the other hand, image guidance during ablation is typically achieved by means of unenhanced CT and/or ultrasound. Different methods are used to improve the detectability of the target lesion during CT-guided ablation in order to overcome this shortcoming [11]. One approach to directly improve lesion visibility is to inject small amounts of contrast agent through an intra-arterial catheter, placed in the hepatic artery [12] - a method that increases the invasiveness of the procedure, requires access to DSA to place the catheter, and works only for lesions with a strong arterial blood supply. Indirect approaches use image co-registration of diagnostic CECT or MR imaging with the corresponding intraprocedural imaging [13-15]. However, co-registration of hepatic lesions can be error-prone.

Another, simple method is to use surrounding anatomical landmarks that can usually be defined on unenhanced $\mathrm{CT}$, like portal or liver vein branches, or distance to liver capsule or other anatomical structures [16]. However, such procedures can be challenging since not all landmarks are visible on unenhanced CT. Image quality is often worse on intra-procedural control scans due to beam-hardening artifacts. Moreover, gross patient motion, patient breathing, and bowel motion, as well as deformation of the liver secondary to the penetration of the probe can all contribute to difficulties when using this approach.

Accordingly, the aim of this study was to investigate whether the detectability of the target lesions in unenhanced CT would affect the outcome of liver ablation procedures done on the basis of unenhanced $\mathrm{CT}$, using the anatomical landmark approach to identify target lesions.

\section{Materials and Methods}

This retrospective study was in accordance with the ethical standards of the institutional research committee and with the 1964 Helsinki declaration and its later amendments.

\section{Patients}

We included all patients who underwent CT-guided hepatic ablation procedures (RFA, MWA, or IRE) in our department between $06 / 2015$ and 06/2018. The decision to perform percutaneous ablation was established in consensus in a multidisciplinary tumor board, attended by hepatobiliary surgeons, oncologists, radiotherapists, pathologists, radiologists, and interventional radiologists. Hepatic tumor ablation was recommended in patients, who were considered illegible for surgical resection and had no extrahepatic tumor burden.

All patients had undergone either contrast-enhanced CT or MRI prior to ablation.

Patients, who had less than four weeks of follow-up, were excluded from the study.

\section{Ablation}

All procedures were performed by experienced interventional radiologists with more than 5 years of experience in abdominal interventions.

As per the standard protocol at our institution, all procedures were performed under general anesthesia. The individual 

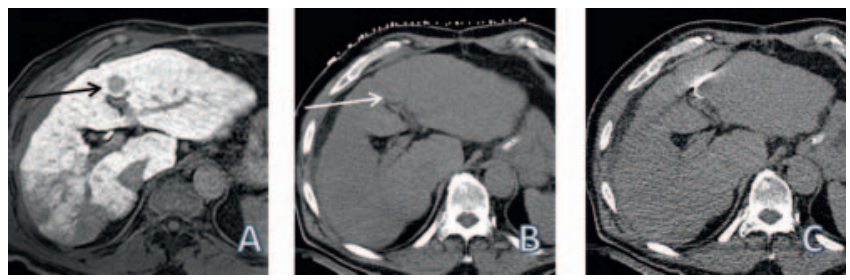

- Fig. 1 Using anatomical landmarks for needle placement. A diagnostic, diffusion-weighted MR image. $\mathbf{B}$ unenhanced $\mathrm{CT}$ image with surface marker grid for planning needle placement (the known lesion is not visible, but the adjacent portal vein branches are well depictable). C RFA applicator in the right position.

- Abb. 1 Nutzung anatomischer Landmarken für Nadelpositionierung.

approach and patient positioning during the ablation were determined by the interventionalist. For planning applicator placement, unenhanced CT was performed and compared to previous images using the anatomical landmark method ( $\triangleright$ Fig. 1). Lesions were defined as visible lesions (DLs) or non-visible lesions (NDLs) if the lesions could or could not be detected by an experienced interventional radiologist. The applicator was positioned using intermittent CT scans in expiratory breath hold.

If needed, overlapping ablation after repositioning of the electrodes was performed until the interventional radiologist felt that tumor ablation should be complete including a safety margin of at least $5-10 \mathrm{~mm}$. The safety margin and the size of the ablation zone were planned according to the size and location of the lesion, independent of its detectability.

Before removing the electrode, a contrast-enhanced tri-phasic CT scan was obtained to verify treatment success and assess immediate complications. Track ablation was performed in all RFA and MWA procedures.

For RFA we used a monopolar system (RF 3000, Boston Scientific Corp, MA, USA) with umbrella-shaped applicators with a diameter of 2-4cm and varying shaft lengths (LeVeen, Boston Scientific Corp, MA, USA). Ablation is performed according to the vendor's ablation protocols.

MWA was performed using the Emprint system (Medtronic, MI, USA) with dedicated antennae with different shaft lengths. We always adhered to the protocols provided by the vendor.

We used the NanoKnife ${ }^{\circledR}$ system (AngioDynamics, Amsterdam, the Netherlands) for IRE with 2 to 5 probes with a tip exposure of $1.5 \mathrm{~cm}$. IRE was performed with 70-90 pulses per probe pair, a pulse length of $90 \mu \mathrm{s}$, and a maximum voltage of $3000 \mathrm{~V}$.

\section{Evaluation of ablation and follow-up}

The size of the ablation zone was measured in the immediate postinterventional contrast-enhanced CT examination, calculating the average diameter ((short + long axis)/2).

Adverse events were assessed according to the CIRSE classification system [17].

Routine follow-up imaging was performed 1 month after ablation and every 3 months thereafter and consisted of either contrast-enhanced multiphasic $\mathrm{CT}$ or contrast-enhanced MRI. Technical efficacy was determined on the basis of the 1-month CT/MRI examination according to the criteria defined by the international working group on image-guided tumor ablation [8].

Incomplete ablation (IA) was defined as the persistence of enhancing areas within the ablation zone or peripheral nodular enhancement within a 10-mm margin at the first follow-up scan four weeks after the procedure.

Local tumor progression (LTP) was defined as recurrent disease within a 10-mm margin during subsequent follow-up.

Intrahepatic progression-free survival (ihPFS) time was defined as the interval between ablation procedure and the first detection of local recurrence or new metastases elsewhere in the liver.

\section{Statistical analysis}

All statistical analyses were performed using SPSS software (version 24; IBM). IA and LTP rates as well as frequency of adverse events (AE) were compared between the groups using the Chisquare test. The lesion size and the size of the ablation zone were compared between the groups using the Mann-Whitney U-test. IhPFS was calculated for all patients using the Kaplan-Meier method and the difference among groups was determined by the log-rank test.

A value of $p<0.05$ was considered statistically significant. All values are expressed as mean \pm standard deviation (SD) or median and interquartile range (IQR).

\section{Results}

\section{Patients and tumors}

A total of 69 patients with 99 malignant hepatic liver lesions were included in the study. Patient characteristics are summarized in - Table 1. The median number of treated tumors per patient was 1 (range 1-3). 59 of all treated lesions were DLs in the planning unenhanced $\mathrm{CT}$ examination and 40 were NDLs.

The mean lesion size showed no statistically significant difference between lesions that were visible and those that were not visible, with $14.9 \pm 0.9 \mathrm{~mm}$ for DLs und $12.9 \pm 0.8 \mathrm{~mm}$ for NDLs $(p=0.28)$.

The type of ablation procedure used is summarized in $\boldsymbol{\vee}$ Table $\mathbf{2}$.

\section{Technical success}

The size of the ablation zone was not significantly different for both groups: $38.8 \pm 1.3 \mathrm{~mm}$ for DLs and $37.1 \pm 1.4 \mathrm{~mm}$ for NDLs $(p=0.41)$.

Incomplete ablation was observed in 2 out of 59 cases (3.4\%; $0.4-11.7 \%$ ) in the DL group and in 2 out of 40 cases (5.0\%; $0.6-16.9 \%)$ in the NDL group, which was also not significantly different $(p=0.69)$.

\section{Adverse events}

AEs were observed in 6 of 69 patients (9\%).

The following AEs were observed: One patient developed pneumothorax, two patients had perihepatic hematomas, two patients had arterioportal fistulae, and one patient was found to have segmental liver infarction due to procedure-related portal vein thrombosis. In two patients, an additional intervention in 
- Table 1 Patients characteristics.

- Tab. 1 Patientencharakteristika.

\begin{tabular}{|c|c|c|}
\hline & & $N=69$ \\
\hline Age (y) & \multicolumn{2}{|l|}{$66.6( \pm 14.8)$} \\
\hline \multirow[t]{2}{*}{ Gender } & Male & $52(75 \%)$ \\
\hline & Female & $17(25 \%)$ \\
\hline \multirow[t]{9}{*}{ Tumor type } & Hepatocellular cancer & $20(29 \%)$ \\
\hline & Cholangiocarcinoma & $9(13 \%)$ \\
\hline & Colorectal metastases & $33(48 \%)$ \\
\hline & Metastases of melanoma & $2(3 \%)$ \\
\hline & Metastases of ovarian cancer & $2(3 \%)$ \\
\hline & Metastases of gastric carcinoma & $1(1 \%)$ \\
\hline & Metastases of pancreas carcinoma & $1(1 \%)$ \\
\hline & Metastases of bronchial carcinoma & $1(1 \%)$ \\
\hline & Metastases of breast cancer & $1(1 \%)$ \\
\hline \multirow[t]{2}{*}{ Liver cirrhosis } & Yes & $14(20 \%)$ \\
\hline & No & $55(80 \%)$ \\
\hline \multirow{4}{*}{$\begin{array}{l}\text { Number of treated } \\
\text { lesions per patient }\end{array}$} & $\mathrm{n}=1$ & $47(68 \%)$ \\
\hline & $\mathrm{n}=2$ & $15(22 \%)$ \\
\hline & $n=3$ & $6(9 \%)$ \\
\hline & $n=4$ & $1(1 \%)$ \\
\hline
\end{tabular}

form of coil embolization (one of arterial bleeding and one of a symptomatic arterioportal fistula) was required (grade 3 ).

All other complications were categorized as grade 1 . There was no procedure-related permanent morbidity or death. All complications were observed in the DL group in 6 out of 59 cases $(10 \%)$, with a statistically significant difference $(p=0.037)$ compared to 0 out of 40 cases ( $0 \%$ in the NDL group.

\section{Follow-up, LTP, and ihPFS}

The mean follow-up was $16.2 \pm 11.7$ months: $14.8 \pm 1.5$ months for patients after ablation of DLs and 18. $2 \pm 1.8$ months for patients after ablation of NDLs.

One patient was lost to follow-up after 4 weeks.

During the follow-up-time, local tumor progression was observed in 10 out of 59 cases (16.9\%) in the DL group and 6 out of 39 cases $(15.4 \%)$ in the NDL group, which was not significantly different $(p=0.84)$.

Using Kaplan-Meier analysis, the mean estimated ihPFS time was $15.5 \pm 2.2$ months for DLs compared to $14.3 \pm 2.4$ months for NDLs $(p=0.84)$. These results are visualized in > Fig. 2 .

\section{Discussion}

This study investigated whether the detectability of target lesions during CT-guided hepatic ablations would influence the technical and oncological success or adverse event rates of ablation proce-
- Table 2 Ablation characteristics.

- Tab. 2 Charakteristika der Ablationen.

\begin{tabular}{|c|c|c|c|}
\hline & & & $\mathrm{N}=99$ \\
\hline \multirow{2}{*}{$\begin{array}{l}\text { Detectability of tumor } \\
\text { in unenhanced } \mathrm{CT}\end{array}$} & \multicolumn{2}{|c|}{ Detectable (DL) } & $59(59 \%)$ \\
\hline & \multicolumn{2}{|c|}{ Non-detectable (NDL) } & $40(40 \%)$ \\
\hline \multirow[t]{6}{*}{ Ablation type } & \multirow[t]{2}{*}{ MWA } & $\mathrm{DL} n=18$ & \multirow[t]{2}{*}{$23(23 \%)$} \\
\hline & & $N D L n=5$ & \\
\hline & \multirow[t]{2}{*}{ RFA } & $\mathrm{DL} \mathrm{n}=24$ & \multirow[t]{2}{*}{$41(41 \%)$} \\
\hline & & NDL $n=17$ & \\
\hline & \multirow[t]{2}{*}{ IRE } & $\mathrm{DL} n=17$ & \multirow[t]{2}{*}{$35(35 \%)$} \\
\hline & & NDL $n=28$ & \\
\hline
\end{tabular}

dures. Our results demonstrated that there was no significant difference comparing the groups with detectable and non-detectable lesions in terms of the completeness of ablation, rates of local recurrence, or intrahepatic recurrence-free survival. We expected that in patients with non-detectable lesions (NDL), the ablation zones would be larger than in patients with detectable lesions (DL) - but this was also not the case. Last, adverse events were even significantly lower in the NDL group, suggesting that they are not connected with the detectability of the target lesion.

Accordingly, when using the "anatomical landmark approach" to ablate non-detectable lesions, the outcome was similar compared with that of patients with detectable lesions. Applying the "anatomical landmark approach" it should be considered that the position of the target lesion in relation to a landmark might be distorted due to patient positioning (e. g., supine vs. prone position) or breathing movements. Therefore, we perform every needle placement and every control CT scan in breath hold under general anesthesia and we attempt to perform ablation in the same patient position as in the preoperative imaging.

The overall rate of local tumor recurrence observed in this study is in line with previously published data, ranging from $6 \%$ to $33 \%$ [18-22]. P Fig. 3 shows an example of an incomplete ablation in one of our patients, most likely due to the adjacency of the liver vein and thus the heat sink effekt. Several studies investigated risk factors associated with partial ablation and local recurrence [23-26]. To our knowledge, there is no previous study investigating the detectability of the target lesion as a potential risk factor.

One study that compared the accuracy of computer-assisted versus cognitive registration for locating liver tumors had shown that non-rigid registration yielded better localization accuracy than cognitive registration performed by the interventional radiologist [27]. However, no clinical outcome was investigated in this study. In other words, the clinical benefit of image registration in liver ablation is largely unknown.

Limiting factors of the presented study include the use of unenhanced CT scans as a criterion for lesion visibility and the lack of additional ultrasound guidance. We generally use unenhanced CT for ablation planning but use contrast agent after 


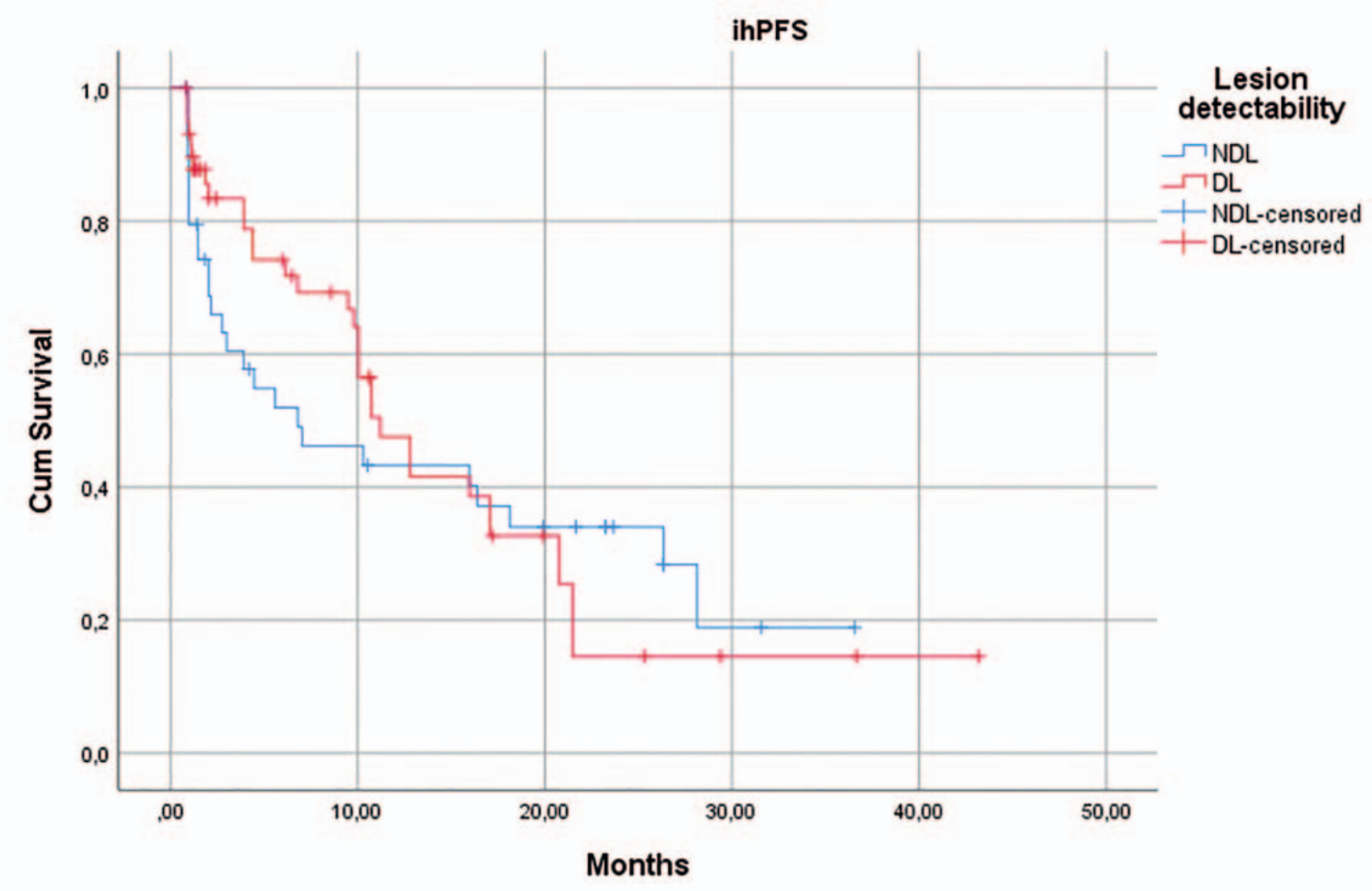

- Fig. 2 Kaplan-Meier curve for intrahepatic progression-free survival.

- Abb. 2 Kaplan-Meier-Kurve für das intrahepatische progressfreie Überleben.
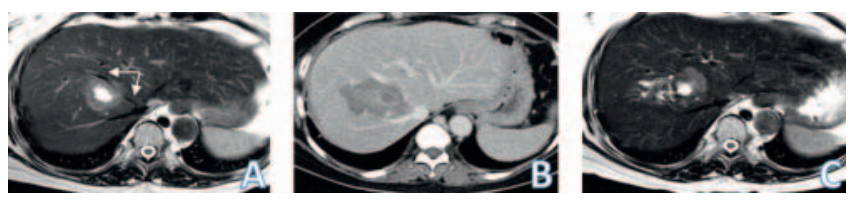

- Fig. 3 Example of an incomplete ablation. A Pre-procedural T2weighted MRI-Image of a colorectal metastasis adjacent to the middle liver vein (arrows). B Post interventional control-CT-scan in hepatic portal phase one day after MWA of the metastasis. C T2weighted MRI-Image four weeks after MWA with detectable residual tumor adjacent to the middle liver vein, in the sense of incomplete ablation, probably due to the heat sink effect.

- Abb. 3 Beispiel einer unvollständigen Ablation. A Preinterventionelles, T2-gewichtetes MRT-Bild einer kolorektalen Metastase angrenzend an die mittlere Lebervene (Pfeile). B Postinterventionelle Kontroll-CT-Untersuchung in venöser Kontrastmittelphase ein Tag nach Mikrowellenablation der Metastase. C T2-gewichtetes MRTBild vier Wochen nach Ablation mit abgrenzbarem Resttumor angrenzend an die mittlere Lebervene, im Sinne einer unvollständigen Ablation, am ehesten aufgrund von heat sink Effekt.

the presumed completion of the procedure in order to evaluate the ablation result. We perform contrast-enhanced imaging only in cases requiring visualization of not only the target lesion but also of critical anatomic structures e.g., the liver hilum - but usually after placement of the ablation probe near the target lesion. Often several rounds of contrast-enhanced CT imaging are required, though the reasonably applied amount of IV contrast is limited. Therefore, we tend to dispense with an initial contrastenhanced CT examination for planning purposes in order to safely be able to perform a contrast-enhanced CT examination in the case of acute complications. Also, anatomical structures, as well as the target lesion, are visible only for a short time after application of contrast agent. Nevertheless, their exact position might change during the procedure as they can be displaced by the puncture needle.

Ultrasound is often used as a stand-alone or assisting technique for tumor ablation. In our institution we perform tumor ablation solely with CT guidance. The addition of US could help depict more NDLs and could be used as a real-time tool for accurate needle placement.

In view of our results, however, there seems to be little need for additional ultrasound for targeting purposes even in patients with NDLs.

Another often used technique is prior lesion marking by intraarterial lipiodol injection. In our experience marking was insufficient in many cases of liver metastases due to poor vascularization. Furthermore, the combination of intraarterial and CT- 
guided interventions is often logistically challenging and places an additional strain on the patient with a further risk of complications. Nevertheless, our experience is based on very few cases and since there are some good results in the published literature [28], this technique should be considered in the appropriate cases.

We included a variety of liver malignancies, including primary and secondary liver tumors, which typically present different features on CT and MRI imaging, such as arterial hyperenhancement and venous washout. Also, the presence or absence of liver cirrhosis generates a different image in diagnostic and interventional imaging. However, the different tumor types and the cases of liver cirrhosis were evenly distributed in the DL and NDL groups, so that we are confident that this would not confound our results.

In conclusion, this study demonstrates that successful ablation of liver tumors that are not detectable on unenhanced CT is possible and safe when using the anatomical landmark method to guide needle placement.

\section{Conflict of Interest}

The authors declare that they have no conflict of interest.

\section{References}

[1] Mahnken A, Pereira P, de Baère T. Interventional oncologic approaches to liver metastases. Radiology 2013; 266: 407-430

[2] Kulaylat M, Gibbs J. Thermoablation of colorectal liver metastasis. J Surg Oncol 2010; 101: 699-705

[3] Meloni M, Chiang J, Laeseke P et al. Microwave ablation in primary and secondary liver tumours: technical and clinical approaches. Int J Hyperthermia 2017; 33: 15-24

[4] Guenette J, Dupuy D. Radiofrequency ablation of colorectal hepatic metastases. J Surg Oncol 2010; 102: 978-987

[5] Lencioni R. Loco-regional treatment of hepatocellular carcinoma. Hepatology 2010; 52: 762-773

[6] Scheffer $\mathrm{H}$, Vroomen L, Nielsen $\mathrm{K}$ et al. Colorectal liver metastatic disease: efficacy of irreversible electroporation-a single-arm phase II clinical trial (COLDFIRE-2 trial). BMC Cancer 2015; 15: 772

[7] Crocetti L, de Baere T, Lencioni R. Quality improvement guidelines for radiofrequency ablation of liver tumours. Cardiovasc Intervent Radiol 2010; 33: 11-17

[8] Ahmed M, Solbiati L, Brace C et al. Image-guided tumor ablation: standardization of terminology and reporting criteria - a 10-year update. Radiology 2014; 273: 241-260

[9] Wells S, Hinshaw ], Lubner M et al. Liver Ablation: Best Practice. Radiol Clin North Am 2015; 53: 933-971

[10] Pua B, Sofocleous C. Imaging to optimize liver tumor ablation. Imaging Med 2010; 2: 433-443

[11] Wood B, Kruecker ], Abi-Jaoudeh $\mathrm{N}$ et al. Navigation systems for ablation. J Vasc Interv Radiol 2010; 21: 257-263
[12] van Tilborg A, Scheffer $\mathrm{H}$, Nielsen $\mathrm{K}$ et al. Transcatheter $\mathrm{CT}$ arterial portography and $\mathrm{CT}$ hepatic arteriography for liver tumor visualization during percutaneous ablation. J Vasc Interv Radiol 2014; 25: 1101-1111

[13] Luu H, Klink C, Niessen W et al. Non-Rigid Registration of Liver CT Images for CT-Guided Ablation of Liver Tumors. PLoS One 2016; 11 : e0161600

[14] Abi-Jaoudeh N, Kruecker J, Kadoury S et al. Multimodality image fusionguided procedures: technique, accuracy, and applications. Cardiovasc Intervent Radiol 2012; 35: 986-998

[15] Appelbaum L, Mahgerefteh S, Sosna J et al. Image-guided fusion and navigation: applications in tumor ablation. Tech Vasc Interv Radiol 2013; 16: $287-295$

[16] Varga E, Pattynama P, Freudenthal A. Manipulation of mental models of anatomy in interventional radiology and its consequences for design of human-computer interaction. Cogn Tech Work 2013; 15: 457-473

[17] Filippiadis D, Binkert C, Pellerin O et al. Cirse Quality Assurance Document and Standards for Classification of Complications: The Cirse Classification System. Cardiovasc Intervent Radiol 2017; 40: 1141-1146

[18] Van Tilborg A, Meijerink M, Sietses C et al. Long-term results of radiofrequency ablation for unresectable colorectal liver metastases: a potentially curative intervention. $\mathrm{Br}$ J Radiol 2011; 84: 556-565

[19] Kurowecki D, Kielar A, Shabana W et al. Incidence of local recurrence 1 year following radiofrequency ablation for hepatocellular carcinoma: a single center experience. J Vasc Interv Radiol 2016; 27: 124

[20] Solbiati L, Ahmed M, Cova L et al. Small liver colorectal metastases treated with percutaneous radiofrequency ablation: local response rate and long-term survival with up to 10-year follow-up. Radiology 2012; 265: 958-968

[21] Livraghi T, Solbiati L, Meloni F et al. Percutaneous radiofrequency ablation of liver metastases in potential candidates for resection: the "testof-time approach". Cancer 2003; 97: 3027-3035

[22] Niessen C, Beyer L, Pregler B et al. Percutaneous Ablation of Hepatic Tumors Using Irreversible Electroporation: A Prospective Safety and Midterm Efficacy Study in 34 Patients. J Vasc Interv Radiol 2016; 27: 480-486

[23] Hori T, Nagata K, Hasuike $S$ et al. Risk factors for the local recurrence of hepatocellular carcinoma after a single session of percutaneous radiofrequency ablation. J Gastroenterol 2003; 38: 977-981

[24] Wiggermann P, Puls R, Vasilj A et al. Thermal ablation of unresectable liver tumors: factors associated with partial ablation and the impact on long-term survival. Med Sci Monit 2012; 18: 88-92

[25] Kim Y, Rhim H, Cho O et al. Intrahepatic recurrence after percutaneous radiofrequency ablation of hepatocellular carcinoma: analysis of the pattern and risk factors. Eur ] Radiol 2006; 59: 432-441

[26] Wang X, Sofocleous C, Erinjeri ] et al. Margin size is an independent predictor of local tumor progression after ablation of colon cancer liver metastases. Cardiovasc Intervent Radiol 2013; 36: 166-175

[27] Boulkhrif $\mathrm{H}$, Luu $\mathrm{H}$, van Walsum T et al. Accuracy of semi-automated versus manual localisation of liver tumours in CT-guided ablation procedures. Eur Radiol 2018; 28: 4978-4984

[28] Takaki H, Yamakado K, Nakatsuka A et al. Computed tomography fluoroscopy-guided radiofrequency ablation following intra-arterial iodized-oil injection for hepatocellular carcinomas invisible on ultrasonographic images. Int J Clin Oncol 2013; 18: 46-53 